DOSSIÊ

\title{
A emergente discussão de uma renda básica universal no Brasil em tempos de pandemia
}

The emerging discussion of implementing a universal basic income in Brazil in times of pandemic

\section{Luiz Alberto de vargas* Walter oliveira**}

DOI: https://doi.org/10.4322/principios.2675-6609.2020.160.006

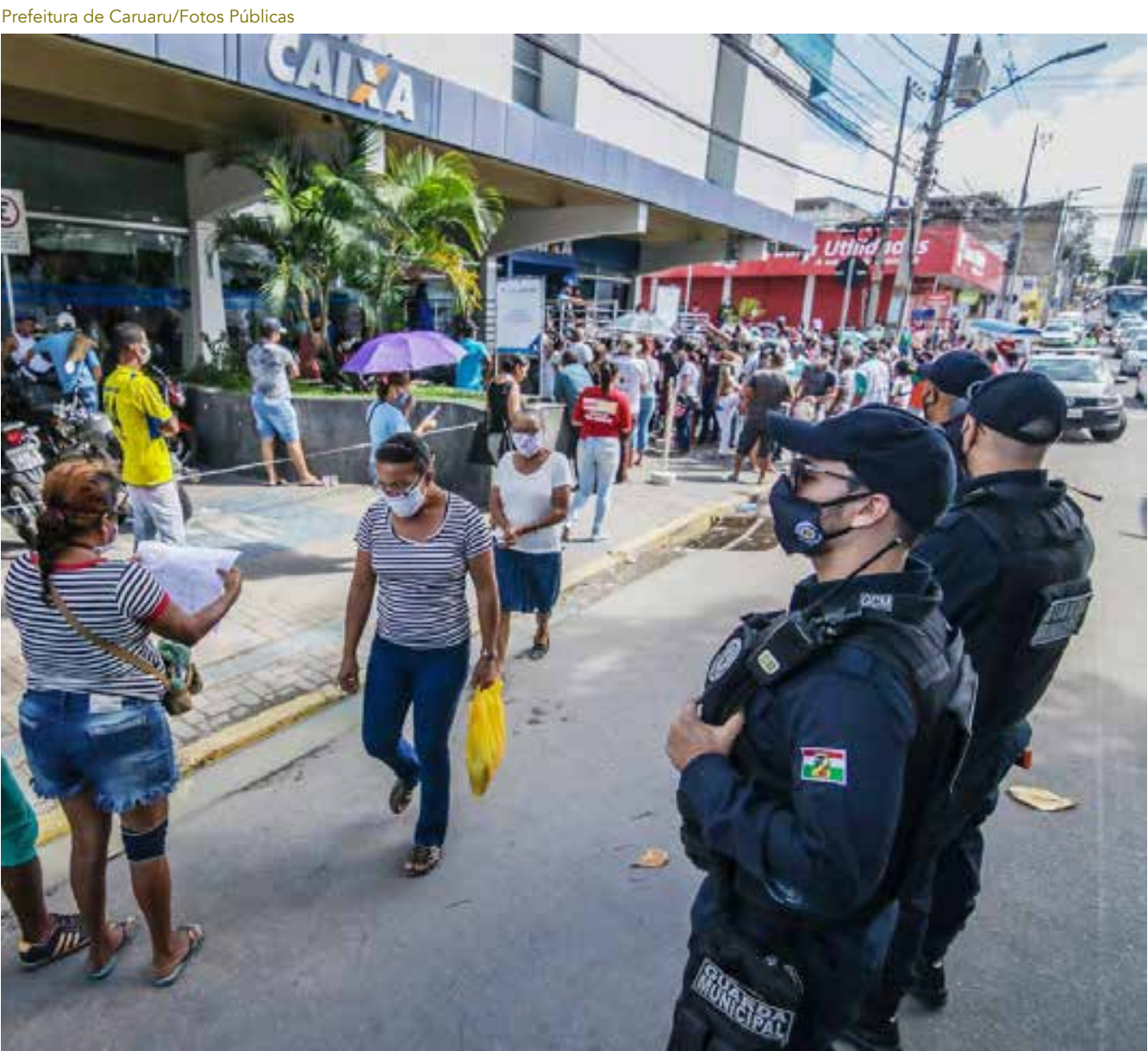

Fila na Caixa Federal em Caruaru (PE) 


\section{RESUMO}

As políticas econômicas marcadamente neoliberais adotadas pelos governos Temer e Bolsonaro favoreceram - e favorecem ainda - a desregulamentação do trabalho, o que, em longo prazo, prejudica o desenvolvimento nacional. A procura pelo auxílio emergencial revelou a existência de milhões de pessoas até então invisíveis (80 milhões de brasileiros) e a paralisação da economia formal, com gravíssimas e rápidas consequências sociais. Os governos dos mais diversos níveis, na sua maior parte, demonstram pouca preocupação em manter empregos e salvar as pequenas e microempresas. Frente a essa realidade, ao ensejo do amplo debate atual sobre o abono emergencial, busca-se examinar as possibilidades de inclusão na agenda política nacional de uma renda básica universal em cumprimento do dever constitucional do Estado de garantir políticas de proteção social e de garantia de renda e emprego.

Palavras- chave: Renda básica. Previdência. Políticas sociais. Cidadania.

\section{ABSTRACT}

The neoliberal economic policies adopted by the Temer and Bolsonaro governments favored - and continue to favor - the increasing deregulation of work. In the long run, this kind of police undermines national development. During the pandemic, the huge demand for emergency aid revealed that 80 million Brazilians needed this kind of financial support and that the interruption of part of formal economic activities had serious consequences. Most governments at all levels show little concern for maintaining jobs and saving small business. In view of this reality and of the current debate on the emergency allowance, this article seeks to examine the possibilities of implementing a universal basic income in the country, in compliance with the constitutional duty of the State to guarantee social protection policies and guarantee income and employment.

Keywords: Basic income. Social security. Social policies. Citizenship. 


\section{INTRODUCC̣̃O: A EVOLUÇ̃̃O DO CONCEITO DE NECESSITADO - DA CARIDADE AOS MENDIGOS À RENDA DE CIDADANIA}

Historicamente, a ajuda aos necessitados dependeu da família, do clã, das comunidades, das irmandades religiosas, das sociedades mutuais, das corporações de ofício, das instituições benemerentes: ajuda aos "seus" e desamparo dos "outros". Essa ajuda tinha natureza caritativa e se sustentava na iniciativa privada, com apoio secundário do poder público. Destinava-se aos desvalidos, aos "perdedores" que ficavam pelo caminho do progresso material e, assim, eram tidos como "benefícios altruístas" — não eram vistos como direitos e não tinham a obrigação de serem reabilitadores ou, mesmo suficientes. O estigma de "mendigos e vagabundos" - que sempre acompanhou os contemplados por tal ajuda - somente passa a mudar a partir da compreensão dos riscos sociais decorrentes da insustentabilidade e da instabilidade sociais causadas pela emergência de uma pobreza "no coração da sociedade" (CASTEL, I998, p. 495). Surgem os Estados de bem-estar social com uma nova visão sobre a marginalização, superando o conceito de assistência caritativa (primeira metade e meados do século XX). Criam-se diversos mecanismos de proteção social: previdência social (incorporação das mútuas sindicais profissionais); proteção contra doenças profissionais; aposentadoria; seguro-desemprego; auxílio família; assistência à saúde; deduções fiscais; benefícios de prestação continuada; serviços básicos públicos e gratuitos (saúde e educação); subsídios (transporte e moradia); salário-mínimo; direitos laborais e de proteção ao emprego; subsídios à contratação e incentivo à negociação coletiva. Todos esses mecanismos estão associados a um conceito particular de marginalização, próprio do Estado de bem-estar social, ligado à condição de trabalhador e ao mito do pleno emprego. Visto o trabalho como um dever do cidadão, um auxílio assistencial aos desempregados se justifica apenas como "ponte" para uma desejável reintegração deles ao mercado de trabalho. Ficam de fora os marginalizados que não se vinculam ao mercado de trabalho.

O destinatário da ajuda social é quem não pode trabalhar e, assim, não pode prover com o seu trabalho o sustento material da sua família. Aquele que não trabalha, seja porque não quer ou porque não pode, é considerado um "cidadão de segunda classe”, um peso para a sociedade, que deve assegurar tão-somente sua manutenção vital — não necessariamente sua reinserção social. Em um contexto amplo de tipos de marginalização ${ }^{1}$, opta-se por discernir os que "merecem ser ajudados" dos que se conformaram definitivamente com sua condição subalterna e, assim, por incompetência ou inação, se "autoexcluíram" de qualquer esforço de reinserção social, interpretada como uma recuperação de sua condição de cidadão. Essa lógica, intrinsicamente discriminatória e funcional à dominação capitalista, fica desnudada a partir da crise dos modelos de economias sociais-democratas, em que o retorno do desemprego em massa evidencia sua natureza estrutural e o desmanche dos Estados de bem-estar volta a

\footnotetext{
Um universo de "perdedores" pode incluir outros tipos de marginalização, sejam decorrentes de infortúnio (velhos, portadores deficiência, doentes); de conduta (prostitutas, drogados, delinquentes); por problemas familiares ou culturais (mulheres presas ao trabalho doméstico ou de cuidado), ou mesmo, por opção pessoal (hippies, revolucionários, intelectuais).
} 
jogar à miséria e ao desamparo parte significativa da população. $\mathrm{O}$ avanço das ideais neoliberais levou a um aumento considerável da miséria, ao mesmo tempo em que reduzia a capacidade dos Estados nacionais em amparar seus cidadãos ${ }^{2}$.

Assistiu-se a um retorno ao malthusianismo, agora sob a forma de necropolítica ${ }^{3}$, com uma marginalização estrutural em que se abandona a ilusão do pleno emprego e passa-se a sustentar "que sempre houve e sempre haverá perdedores". Uma massa impressionante de desamparados (trabalhadores desempregados desalentados, "precarizados", informais, falsos "autônomos" desassistidos de serviços públicos essenciais e abandonados pelas políticas de seguridade sociais) passa a exigir dos Estados nacionais estratégias de convivência com os permanentemente marginalizados, criando-se um verdadeiro apartheid social.

Esse mundo globalizado, perverso e individualista, em marcha batida para o caos, parece infenso a qualquer proposta de alteração de rumos, indiferente a qualquer crítica.

Isso até o momento em que a pandemia torna todos nós, simultaneamente, mais reflexivos e mais sensíveis aos problemas do mundo. Subitamente, a crise sanitária parece ter criado uma inusitada consciência a respeito da insustentabilidade do mundo atual. Proposições até então tidas como utópicas e inviáveis agora passam a ser tomadas a sério ${ }^{4}$.

Entram em cena diversas estratégias para enfrentar esse problema, talvez o mais grave que enfrenta o mundo neste início de século. Direita e esquerda, aparentemente, parecem concordar que mecanismos de transferência para os setores menos favorecidos possam ser parte da resposta.

Neste artigo pretende-se contextualizar como o atual debate sobre o abono emergencial e sua manutenção (ou substituição por um benefício equivalente) pode descortinar uma maior compreensão sobre a urgência de uma renda básica universal que caminhe no sentido de cumprir o dever constitucional do Estado: garantir políticas de proteção social e de garantia de renda e emprego.

\section{POR QUE A RENDA BÁSICA UNIVERSAL (RBU) É ESSENCIAL AO DEBATE DO BRASIL DE HOJE? A DISCUSSÃO PÓS-PANDEMIA}

A discussão a respeito de uma renda básica universal (RBU) torna-se maior e mais urgente em tempos de pandemia. No mundo do trabalho, um dos mais dramáti-

2 Quase metade da população mundial (3,4 bilhões de pessoas) ainda luta para satisfazer suas necessidades básicas, segundo o Banco Mundial (QUASE..., 2020).

3 "Neste malthusianismo regenerado e subterrâneo a estratégia da necropolítica não é realizar um massacre a olhos nus, nem tampouco o de insuflar discursos beligerantes. É fazer da morte um acontecimento invisível e sobre a qual se possa mesmo negar a existência" (PIMENTEL FILHO, 2020, p. 141).

4 Assim, surgem ou revivem ideias de "decrescimento"; de regulação dos fluxos internacionais de capital (taxa Tobin); da taxação das grandes fortunas; do não pagamento das dívidas externas dos países do Terceiro Mundo; de uma nova moeda internacional para as relações comerciais internacionais; de regulação dos mercados financeiros e controles mais severos sobre a atuação das empresas transnacionais, que passam, surpreendentemente, à ordem do dia. 
cos efeitos dos tempos insólitos - a par da aceleração de processos que já avançavam na surdina, como a digitalização do trabalho e a expansão do trabalho domiciliar é a maior visibilidade de graves distorções sociais que, até então, passavam pouco percebidas, como o vertiginoso aumento da desigualdade e a importância, no caso brasileiro, de uma crescente economia informal ${ }^{5}$ (atividade econômica e emprego ${ }^{6}$ ). A pandemia do Covid-I9 paralisou subitamente a economia nacional, atingindo fortemente o setor informal - com previsíveis graves consequências sociais e políticas, mas, também, ameaçando abalar a economia como um todo ${ }^{7}$. Às pressas, o governo brasileiro e o Congresso Nacional, em inédito consenso, estenderam um benefício emergencial de $\mathrm{R} \$ 600,00$ por três meses a trabalhadores até então esquecidos, e, mesmo, não percebidos, tanto que os gastos totais serão superiores àqueles previstos pelo governo ${ }^{8}$.

A surpresa também ocorreu em relação aos efeitos benfazejos do auxílio emergencial sobre a economia ${ }^{9}$, verificando-se um saudável retorno a esquecidas lições do pensamento keynesiano, bem na contramão de ideias neoliberais que propõem ainda maiores rigorismos fiscais - algo que, na prática, apenas agravaria ainda mais a recessão econômica ${ }^{\mathrm{IO}}$. O sucesso do abono emergencial e a ousadia que as circunstâncias tornaram inevitável, a de enfrentar os dogmas do pensamento econômico dominante, têm levado economistas mais lúcidos à iconoclastia de propor o fim dos limites constitucionais do teto de gastos e a adoção de políticas vigorosas de

5 Entende-se que a economia informal é composta pelas atividades econômicas que produzem bens e serviços com a finalidade de gerar emprego e renda, com emprego de trabalhadores com contratos de trabalho formalizados ou não. Todavia, a precisão do conceito de setor informal está em debate, como noticia o Blog do Instituto Brasileiro de Economia. Cf. Olinto (2020).

6 Tendencialmente, a crise econômica tem levado ao deslocamento do setor formal para o informal: de 2012 a 2019, a participação na economia do setor informal cresceu de 30\% para 33\%, com queda equivalente do setor formal, de 50,7\% para 47\% (OLINTO, 2020).

7 O setor informal, segundo o IBGE, é composto pelos produtores de bens e serviços que geram ocupação e renda e operam com baixo nível de organização, com alguma ou nenhuma divisão entre trabalho e capital como fatores de produção e em pequena escala, sendo ou não formalmente constituídos. Essa economia não formalizada movimentou cerca de $\mathrm{R} \$ 1,12$ trilhão em 2019, valor semelhante às economias da Suécia e Suíça (ECONOMIA..., 2019).

8 Esse prognóstico surpreendeu o governo, que esperava um gasto de R\$ 124 bilhões (fonte: Tesouro Nacional) - equivalente à redução de gastos prevista pela reforma previdenciária —, quando, pelos cálculos da Instituição Fiscal Independente, o gasto em três meses chegará a R\$154,4 bilhões, beneficiando 79,9 milhões de brasileiros (CASTRO, 2020). O auxílio emergencial já foi solicitado por $43 \%$ da população brasileira; e, destes, apenas $60 \%$ receberam ao menos uma parcela do dinheiro (COSTA; RIZZOTTO; LOBATO, 2020).

9 O auxílio emergencial é um benefício financeiro destinado aos trabalhadores informais, microempreendedores individuais (MEI), autônomos e desempregados, e tem por objetivo fornecer proteção emergencial no período de enfrentamento à crise causada pela pandemia do coronavírus. Segundo estudo da economista Débora Freire (UFMG), a concessão do benefício emergencial implicou um "desvio" de 45\% na queda do PIB do trimestre. Assim, se o PIB cair 1 ponto percentual, haverá a mitigação de 0,45 p.p. por efeito da renda básica. No caso de benefício pago até o final do ano, o impacto será de 0,55 p.p. do PIB. O impacto positivo nas receitas fiscais cobriria $45 \%$ do custo da renda básica (NASSIF, 2020).

$10 \mathrm{Em}$ sociedades heterogêneas, a transferência de renda para setores menos favorecidos amplia a demanda agregada, criando um amplo mercado interno de consumo e beneficiando toda a economia. No caso da economia brasileira, em recessão, não há riscos de pressões inflacionárias (CASTRO, 2013). 
expansão dos gastos públicos ${ }^{\mathrm{II}}$ - algo, aliás, que não discrepa do que tem sido feito pela maioria dos países desenvolvidos (DIEESE, 2020).

Todos têm destinado "vultosos recursos financeiros para a sustentação do isolamento fiscal, aumentando a dívida pública ou emitindo moeda, além de conferir às empresas empréstimos a fundo perdido, feito diretamente pelos governos, com a única contrapartida de manutenção dos empregos" (COELHO, 2020).

É nesse contexto que surge o debate pela implementação de uma renda básica universal, que substituiria a política provisória e focalizada de transferência de renda, expressa na concessão do abono emergencial, por uma política permanente e universal de renda mínima, ainda que tais avanços necessariamente impliquem uma revisão da emenda constitucional $n^{\circ} 95$ (sobre o teto de gastos orçamentários) e da Lei de Responsabilidade Fiscal ${ }^{12}$.

\section{O QUEE É A RENDA BÁSICA UNIVERSAL?}

De Manitoba (Canadá) à Finlândia, diversas experiências de transferência de renda estão sendo realizadas pelo mundo. O próprio papa Francisco fez uma declaração a favor da renda universal. No Brasil, há a experiência exitosa da criação, pela Prefeitura de Maricá, na região metropolitana do Rio de Janeiro, da "mumbu-

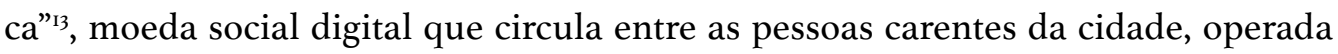
pelo Banco Comunitário. A mumbuca, além de proporcionar uma substantiva trans-

11 "Não há como enfrentar a crise atual sem expansão substantiva dos gastos públicos, seja para sustentar a folha de salários, seja para garantir solvência às empresas, em especial as micro e pequenas, seja para evitar uma debacle no sistema bancário. Mais do que isso, cabe salientar que essa ação estatal deverá, necessariamente, ser financiada por expansão do endividamento público ou por emissão monetária. Isso implica que as regras fiscais vigentes, algumas previstas na Constituição Federal de 1988, sejam abandonadas." (MUNDOS DO TRABALHO, 2020)

12 A lei complementar $n^{\circ} 101$, de 4/5/2000, chamada de Lei de Responsabilidade Fiscal, estabelece normas de finanças públicas voltadas para a responsabilidade na gestão fiscal e estabelece no art. $1^{\circ}$, $\S 1^{\circ}$, que pressupõe essa responsabilidade, a ação planejada e transparente em que se previnem riscos e corrigem-se desvios capazes de afetar o equilíbrio das contas públicas, mediante o cumprimento de metas de resultados entre receitas e despesas. A lei pressupõe inalteráveis os fatores da ação planejada para o resultado de uma gestão fiscal para o equilíbrio das contas públicas. Todavia, alterados esses fatores, inexistirá todo o resto constante no planejamento da ação, e o resultado final de equilíbrio das contas públicas não se verificará. Isso ocorreu, por exemplo, na adoção pelo Governo Federal (governos Temer e Bolsonaro) de uma política de desregulamentação e precarização do trabalho no país, o que resultou em mais desemprego e desassistência social agora agudizada pela pandemia de covid-19. Consequentemente, essa lei não pode ser tomada como óbice à realização dos objetivos fundamentais da República de promover o bem de todos, de erradicar a pobreza e a marginalização e de redução das desigualdades sociais, principalmente no momento de grave crise econômica, de baixo crescimento do PIB e, agudizando tudo isso, de epidemia de covid-19.

13 Nome derivado do rio que corta vários bairros da cidade. A mumbuca é destinada à parcela da população que recebe o cartão Mumbuca. Na prática é "um cartão de débito pré-pago no qual é depositado mensalmente um crédito de 70 mumbucas, equivalentes a exatos R\$70. Está previsto um aumento desse valor para 140 mumbucas em um futuro próximo. O cartão pode ser usado somente nos locais comerciais registrados dentro do município. Para esse esquema funcionar a contento, é necessária uma infraestrutura para a disponibilização e leitura dos cartões, bem como a ativa participação do governo da cidade, responsável por injetar o dinheiro no sistema. Além disso, é muito recomendável que os beneficiários também tenham acesso a cursos e atividades ligados à educação financeira e inclusão social, oferecidos pela prefeitura e pelo banco comunitário." (CERNEV; PROENÇA, 2016). 


\section{A renda básica universal \\ tem também uma dimensão \\ estratégica, qual seja a de \\ fazer aparecer o caráter social \\ do trabalho não mais como \\ a mera existência monetária \\ da mercadoria, na margem da \\ produção real, mas como meio \\ de enfrentar as crises gerais de \\ produção e comércio}

ferência de renda, funciona também como elemento dinamizador da economia da cidade, envolvendo mais de um quarto da população local e representando já um dos mais importantes experimentos de renda básica realizados no país (INSTITUTO PALMAS, 20I8).

A ideia de assegurar aos moradores de determinado território uma renda mínima com a finalidade de garantir a satisfação de suas necessidades básicas é antiga. Autores como Eduardo Suplicy (2020), identificam sua origem na Utopia de Thomas Morus $^{14}$. Ao longo da história, pode-se identificar essa preocupação em prover ajuda aos necessitados como um mecanismo de solidariedade essencial à própria sobrevivência da espécie e, por isso, é compreensível que a consciência sobre sua importância para a coesão social tenha evoluído ao longo do tempo (ENGELS, 200o), variando sua natureza e intensidade de acordo com as condições materiais em cada momento histórico. Pode-se dizer, assim, que mecanismos de garantia da sobrevivência e do bem-estar de toda a população como meio de realização da justiça social representam o acúmulo das experiências históricas que demonstraram sua imprescindibilidade para a coesão do tecido social. Chegado o momento histórico em que empregar a todos já não é mais possível ${ }^{15}$, como assegurar a sobrevivência de uma maioria de alijados da sobrevivência pelos frutos exclusivos do próprio trabalho?

A resposta dada pela direita política é consentânea com o entendimento de

14 Segundo o mesmo autor, Thomas Paine, Bertrand Russel, J. Rawls e James Tobin também se inscrevem entre os que propugnaram por uma renda básica universal.

15 Conforme Cheng Li, com base no pensamento de Hariri, a imensa revolução social provocada pela inteligência artificial faz nascer uma "classe social sem função econômica", que substitui o "proletariado" tradicional e até mesmo esvazia a classe média existente, algo que torna a RBU item prioritário da agenda internacional, chamando a atenção da elite mundial, preocupada com o profundo impacto econômico que a mudança pode ter no sistema político mundial (LI, 2016, p. 15-17). 
que os marginalizados pelo mercado de trabalho são "loosers"16 a serem amparados, na mesma lógica de "cidadania de segunda classe" pela qual a sociedade admite sua obrigação de lhes oferecer um auxílio de emergência, mas não de assegurar os meios necessários para uma vida digna ${ }^{17}$. A ideia de um "imposto de renda negativo" foi apresentada por Milton Friedman (I975) supostamente como uma evolução das políticas de bem-estar social. Consiste na criação de um limite mínimo de ganhos para cada indivíduo, de forma que aqueles que têm rendimentos abaixo desse limite terão a diferença paga pelo governo. Sua principal qualidade, segundo seus proponentes, seria a "focalização" ${ }^{\text {, }}$ ou seja, atingiria apenas os que "realmente precisam", o que exige uma forte política de fiscalização e, também, a comprovação por parte dos que requeiram o benefício, bem como o acoplamento a políticas de capacitação e recolocação profissional, de forma que o pagamento do benefício não exceda os períodos em que o auxílio seja efetivamente necessário. Outra faceta perversa da proposta, nem sempre explicitamente apresentada por seus defensores, é a de que a concessão de uma renda básica levaria a uma menor responsabilidade do Estado, implicando uma redução dos gastos com serviços públicos. Assim, a proposta se alinha com as conhecidas teorias de substituição das prestações de serviços públicos por vouchers, tão ao gosto do pensamento neoliberal (ROCKWELL, 20I4).

A proposta de economistas de esquerda é outra: a renda básica universal ${ }^{19}$. A RBU é apresentada como herdeira natural das estratégias reformistas de "desmercantilização" do mercado e de redução da jornada de trabalho como forma de aumentar a escassez da mão de obra, com elevação dos salários. Mas não se limita a isso. A renda básica universal tem também uma dimensão estratégica, qual seja a de fazer aparecer o caráter social do trabalho não mais como a mera existência monetária da mercadoria, na margem da produção real, mas como meio de enfrentar as crises gerais de produção e comércio, independentemente da crise de dinheiro (capital-dinheiro).

16 Para os neoliberais, o valor de um benefício assistencial deve ser propositalmente baixo e estigmatizante para diminuir sua procura. Nesse sentido, reconhecê-lo com um direito será a pior das estratégias, levando a um aumento astronômico do número de beneficiários. O assistencialismo, assim, deve ser preferencialmente privado e facultativo, baseado no "princípio do estímulo à independência e à autoajuda, reforçando também por toda a sociedade as virtudes da autossuficiência e da autonomia" (ROTHBARD, 2020).

17 Exatamente por entender que qualquer proposta de transferência de renda implica necessariamente a aceitação desse descompromisso do Estado com o pleno emprego, autores progressistas como Guy Aznar e André Gorz se manifestaram contra a renda básica universal (SILVA, 2017).

18 Não necessariamente políticas focalizadas se opõem a políticas universais. Vistas como uma importante complementação para a racionalização e eficiência de gastos em programas sociais, políticas bem focalizadas mostram-se particularmente difíceis no Brasil, onde tradicionalmente uma grande parcela dos recursos públicos é capturada pelas camadas mais favorecidas da população (MELLO, 2004), chegando-se ao paradoxo de os custos de focalização serem iguais ou superiores ao total dos gastos com o próprio programa social. Nesses casos, é bem mais barato e racional pagar o benefício para todos, dispensando-se custos de focalização.

19 Desde 1968, quando cinco economistas de esquerda (John Kenneth Galbraith, Harold Watts, James Tobin, Paul Samuelson e Robert Lampman) encabeçaram uma petição com mais de 1.200 economistas pedindo a implantação de uma RBU (BASIC INCOME EARTH NETWORK, 2020), a proposta tem-se tornado, nos últimos tempos, ponto de convergência nos programas de vários partidos de esquerda, podendo-se citar, mais recentemente, a aprovação de um programa de renda mínima pela coalização de esquerda que governa a Espanha (PSOE, Podemos, partidos regionais) (DOMBEY; SANDBU, 2020). 
De certo, como foi concebida por autores neoclássicos - e mesmo neoliberais como Milton Friedman - , uma transferência de renda, desde que parcial e moderada, pode ser tolerável, desde que não altere os preços relativos e garanta a prevalência das chamadas "leis de mercado". Mas o potencial emancipador das propostas de RBU não pode ser subestimado. A RBU representa um rompimento com a lógica de mercantilização de todas as dimensões da vida, colocando em questão a ideia de um homo economicus a exigir uma racionalidade egoísta em que o mercado se apresenta como única alternativa possível. Por outro lado, uma efetiva RBU, cumprindo os critérios de suficiência e universalidade, seria fator inestimável para reduzir a assimetria entre capital e trabalho à medida que reduziria o excesso da oferta de força de trabalho e contribuiria como fator de empoderamento da classe trabalhadora em luta por melhores condições de vida, impulsionando, ademais, a elevação da consciência dos trabalhadores - e da sociedade em geral - a respeito da necessidade de, através das lutas sociais e políticas, pôr limites ao capitalismo virótico e destrutivo (ANTUNES, 2020). Esse círculo virtuoso pode mesmo, no limite, levar água ao moinho da superação do modo de produção capitalista.

A RBU pode ser definida como um pagamento periódico em dinheiro entregue de modo incondicional a todos individualmente, sem necessidade de testes de meios ou requisitos de trabalho (RBRB, 2020). Assim, temos as cinco características que a diferenciam de outras propostas de transferência de renda: a) é periódica, paga em intervalos regulares - e não um subsídio único; b) é paga em dinheiro ou em um meio de troca apropriado, permitindo que seus beneficiários decidam em que gastar; c) é individual - e não paga, por exemplo, para as famílias; d) é universal, paga a todos; e) é incondicional, paga sem comprovação de renda ou outras exigências (como trabalhar ou demonstrar vontade de trabalhar $)^{20}$.

A importância de que esse pagamento seja universal e incondicional é a de que se trata de um "direito de cidadania", seja porque não se trata de ajuda estigmatizante, seja porque nada mais é do que o cumprimento do dever do Estado em garantir vida digna a seus cidadãos. Tal proposição torna-se plenamente plausível - e quase inevitável - a partir do abandono da ideia do pleno emprego e da constatação de que, no futuro, o emprego se tornará dramaticamente escasso e será impossível assegurar a todos uma vida digna apenas pela oferta de postos de trabalho ${ }^{21}$.

Assim, a RBU não se opõe à bandeira de "trabalhar menos para trabalharem todos" (AZNAR, I995), mas a leva adiante. No futuro, a RBU poderá funcionar como um rendimento de manutenção que poderá ser complementado por uma "segunda renda" (DANERIS, 20I8, p. 93) para quem quiser ganhar mais ou, então, como uma liberação do trabalho excessivo para que o indivíduo possa se dedicar a ocupações

20 "Uma renda básica, em outras palavras, é uma renda que (1) não se restringe àqueles que se dispõem a trabalhar, (2) é disponível ex ante, (3) é garantida independentemente da situação familiar e (4) não varia segundo o lugar de residência." (PARIJS, 1994)

21 A pandemia torna urgente esse debate, a ponto de a ONU, em seu site, em 6 de maio de 2020, publicar matéria preconizando a RBU para evitar "um desastre econômico para um grande número de pessoas em todo o mundo" (COVID..., 2020). 
menos rentáveis, como podem ser as atividades domésticas, artísticas, lúdicas ou benemerentes (PARIJS, 20I4). Cada um será "livre para escolher a área de interesse para desenvolver suas atividades laborais, melhorando a autoestima e qualidade de vida" (RBRB, 2020). Nesse sentido, a ideia da RBU dialoga com outras propostas emancipatórias, como a "sociedade dualista" de André Gorz, a "cidadania social" de Alain Supiot ou a "conversão ecológica" de Dominique Méda (2019).

A incondicionalidade também servirá para reduzir a resistência de setores da classe-média, tradicionalmente avessa a concessões às parcelas menos favorecidas da população (SOUZA, 20I8), já que será um benefício para todos. Por outro lado, a desnecessidade de uma dispendiosa estrutura burocrática para classificação, seleção e fiscalização para discernir entre os "que precisam" e os "que não precisam" da RBU — já que todos, como cidadãos, fazem jus a ela — tornará muito simples e barato o procedimento de concessão do benefício.

Parece igualmente importante conceituar corretamente a renda básica não como uma mera "renda mínima vital"22 destinada a erradicar a pobreza, mas como um programa destinado a garantir uma vida digna para todos ${ }^{23}$. Assim, a renda básica não é uma renda mínima, mas se define como uma quantia de dinheiro suficiente para suprir necessidades fundamentais de cada indivíduo. Tem caráter libertário (BRANCAGLIONE, 20I4), e não meramente assistencial.

Certamente, não se pode esperar que se possa instituí-la de imediato e sem grande resistência política, mas é preciso entender completamente a proposta, sob pena de desfigurar sua compreensão, concebendo-a como mais um projeto de auxílio assistencial.

Por isso mesmo, não se cogita da RBU que substitua benefícios previdenciários de nenhum tipo ou que justifique a redução de serviços públicos. Ela será mais um direito social que já pode - e deve - ser colocado a serviço da cidadania por um inegável progresso material para o qual todos contribuímos - e que, agora, deve ser mais bem distribuído - , servindo, assim, para abrir caminho para um mundo de maior igualdade e bem-estar social.

\section{BRASIL NA PANDEMIA: UM DEBATE ACELERADO POR UMA CRISE INÉDITA E INESPERADA. AS DISPUTAS EM TORNO DO BENEFÍCIO EMERGENCIAL}

O debate sobre a RBU torna-se premente a partir da constatação de que a pandemia não cessará em poucos meses, como previam os mais otimistas, que a recuperação da economia será lenta e que, provavelmente, não se retornará nem mesmo aos modestos patamares de crescimento econômico anteriores à pandemia.

22 Recentemente, a Espanha aprovou uma "renda mínima vital", com valor entre 462 euros (para uma pessoa que vive sozinha) e 1.015 euros (para um casal com três ou mais filhos), com o objetivo de reduzir a pobreza extrema, beneficiando 12 milhões de pessoas (RENDA..., 2020).

23 A ideia de uma renda que seja "suficiente para uma vida digna" parece essencial para que se evitem os riscos de uma "dualização" da cidadania, com a ampliação de situações de discriminação e marginalização dos que não trabalham. 
Surge um consenso a respeito da prorrogação do benefício emergencial e sua substituição por algum outro benefício de transferência de renda, muito próximo de uma renda básica.

A disputa pela natureza, periodicidade e dimensão do auxílio marca todo o debate sobre o novo Renda Brasil"24. Na linha de um "imposto de renda negativo", o que o Governo Federal propõe é um "novo Bolsa Família”, com um valor não superior ao atual ${ }^{25}$, financiado pelo simples deslocamento de vários gastos de natureza previdenciária e assistencial para atender a esse novo benefício, não cogitando de aumento da carga tributária ${ }^{26}$. Já para a oposição se trata de transformar o Renda Brasil na versão mais aproximada possível de uma RBU, de forma que seja permanente, universal e de mais alto valor possível.

O "cabo de guerra" do debate político iniciou-se com as divergências a respeito da prorrogação do benefício emergencial por mais dois meses ou até o final do ano; sua redução para $\mathrm{R}$ \$ 200, com a clara finalidade de "carregar" o valor de $\mathrm{R} \$$ 600 para um eventual Renda Brasil ${ }^{27}$; a definição da natureza individual ou familiar do benefício; a fixação de uma "linha de corte" para a concessão do benefício; o estabelecimento de uma forma exclusiva de financiamento; sua substituição ou não por outros benefícios, e sua vinculação ou não ao salário-mínimo.

O debate prossegue agora, especialmente a respeito do financiamento do benefício, sendo um lugar-comum dos setores neoliberais que uma RBU "não cabe no orçamento público brasileiro", algo que, em meio a uma crise econômica sem precedentes, parece fazer pouco sentido. Ao contrário do que recomendam economistas dos mais diversos matizes ${ }^{28}$, que preconizam urgentes medidas contracíclicas capazes de diminuir o impacto recessivo que ameaça destroçar o tecido produtivo brasileiro, uma visão ortodoxa e superada que ainda comanda as decisões econômicas governamentais insiste em manter uma política de laissez faire, indiferente e de negação, como se a crise pudesse ser superada por si só, pelo simples decurso do tempo.

Parece evidente que, a partir da inegável necessidade de ampliar vigorosamente o gasto público, dever-se-ia aproveitar este momento para alterar o modelo tributário brasileiro, altamente regressivo e uma das causas da imensa desigualda-

24 O governo pretende propor um projeto, com base em estudo da Fundação Getúlio Vargas (FGV), que substituiria o Bolsa Família, o Benefício de Prestação Continuada, o salário-família e a dedução por dependente familiar do imposto de renda por um benefício único, para famílias de baixa renda, por criança até certa idade.

25 O valor de cada benefício é de $\mathrm{R} \$ 41$, e cada família pode acumular até cinco benefícios por mês, chegando a R\$205.

26 Até mesmo porque o governo insiste em não estender para 2021 a liberação da limitação do teto de gastos orçamentários previsto na emenda constitucional $n^{\circ} 95$.

27 Uma primeira proposta governamental nesse sentido foi o pagamento do benefício em duas vezes de $R \$ 300$; a segunda proposta previa três vezes de $R \$ 300$, três vezes de $R \$ 200$ ou três vezes de $R \$ 100$. Uma terceira proposta foi de mais duas vezes de $\mathrm{R} \$ 600$.

28 De Luiz Gonzaga Belluzzo a Armínio Fraga, todos se colocam de acordo em que a recuperação da economia brasileira e de outros países só será possível com um novo desenho da economia de mercado, especialmente em relação ao papel do Estado (VILELA, 2020). 


\section{Uma fonte específica de enorme importância é o imposto sobre} grandes fortunas (IGF), previsto na Constituição, mas não regulamentado. A previsão constitucional é uma enorme vantagem. Esse imposto teria dupla função: desconcentrar renda no topo da pirâmide e a distribuir aos demais segmentos

de no país ${ }^{29}$. Entretanto, essa não parece ser a intenção governamental, que cogita a transformação do auxílio emergencial em novo "Bolsa Família" pela simples fusão de benefícios já existentes ${ }^{30}$. Na mesma linha, há outras propostas que, recusando enfrentar o grave (e real) problema da desigualdade, propõem a simples troca de benefício ${ }^{31}$.

\section{COMO PAGAR A RBU?}

Em tom de alarme, fala-se da impossibilidade de financiamento da renda básica universal, ou mesmo de uma ampliação do abono emergencial, com a mesma ladainha que nada mais significa do que a negação do dever primário do Estado: o de assegurar a provisão de um sistema de proteção social, de um conjunto integrado de ações com competência dos poderes públicos para organizar e iniciar essas ações de gerar mecanismos de proteção como, por exemplo, universalizar a cobertura do benefício da RBU, o que combina com o expresso no artigo I96 da Constituição da República.

A história parece se repetir. Em outros tempos de depressão, o PIB dos EUA a

29 Nesse sentido, estudo coordenado pelo economista Eduardo Fagnani, no âmbito da Associação Nacional dos Auditores Fiscais da Receita Federal do Brasil (Anfip) e da Federação Nacional do Fisco Estadual e Distrital (Fenafisco), denominado "Reforma justa e solidária", levou à apresentação, pela deputada Jandira Feghali (PCdoB-RJ), da emenda substitutiva $n^{\circ} 178$ à proposta de emenda constitucional (PEC) n 45 (sobre a reforma fiscal), que tramita na Câmara Federal (BRASIL, 2019).

30 Exemplo desse descompromisso com aumentar a arrecadação é o estudo da FGV pelo qual seria criado um benefício para crianças em famílias de baixa renda, com um valor médio de R\$ 60 por criança, que fundiria o Bolsa Família, o abono salarial (PIS), a dedução do imposto de renda e o salário-família pela simples transferência dos recursos orçamentários desses benefícios (R\$ 52 bilhões) a um novo Renda Brasil, algo que ocorreria sem qualquer aumento de receita.

31 Pela proposta do economista Samuel Pessôa, haveria uma renda básica de cidadania de R\$406, a preços de 2017, com redução, pela metade, de todos os benefícios permanentes, previdenciários e assistenciais pagos pelo setor público (DUQUE, 2020). 
partir de 1930 também sofreu uma sequência de quedas ininterruptas. A solução que aquele país encontrou deveria servir de exemplo para todas as crises econômicas provocadas pela recessão. Quando, em I933, Franklin D. Roosevelt assumiu a Presidência da República, lançou o New Deal porque à época o PIB correspondia a 56\% do de I929, $25 \%$ dos trabalhadores americanos estavam desempregados e a renda per capita no período de I929 a I933 havia variado de US\$ 700 para US\$ 373. O New Deal pode ser caracterizado como um conjunto de medidas regulatórias e de programas de emergência de geração de emprego e renda, que gerou, como decorrência, extensa rede de assistência social para viabilizar um auxílio imediato à população. Esse era o principal programa de governo de Roosevelt, com o Estado desempenhando papel central na indispensável recuperação econômica, dada a incapacidade da iniciativa privada e dos agentes de mercado de se autorregularem em níveis adequados de emprego, produção e consumo (LIMONCIC, 2009).

O caso dos EUA serve para mostrar que o papel do Estado é imprescindível na promoção e provisão de um sistema de proteção social. A criação dessas redes de proteção social pelo Estado tornou-se generalizada na Europa após a Segunda Guerra e caracterizou o chamado Estado de bem-estar social.

No Brasil, a lei n. I0.835, de 8/1/2004, institui a renda básica de cidadania, "que se constituirá no direito de todos os brasileiros residentes no País e estrangeiros residentes há pelo menos 5 (cinco) anos no Brasil, não importando sua condição socioeconômica, receberem, anualmente, um benefício monetário”. Todavia essa importantíssima lei não se tornou efetiva por ausência de "interesse político na implementação da renda de cidadania nos moldes previstos, para todos e sem condicionantes" (LAZZARIN, 2020), uma vez que condicionada às "possibilidades orçamentárias".

A RBU pode ser financiada por diversas fontes ou por fonte específica, como um imposto sobre os ganhos decorrentes da especulação monetária ou dos dividendos (LAZZARIN, 2020), impostos patrimoniais sobre terrenos ou imóveis, imposto sobre herança, reforma tributária progressiva etc. ${ }^{32}$

Uma fonte específica de enorme importância é o imposto sobre grandes fortunas (IGF), previsto na Constituição, mas não regulamentado. A previsão constitucional é uma enorme vantagem ${ }^{33}$. Esse imposto teria dupla função: desconcentrar renda no topo da pirâmide e a distribuir aos demais segmentos. Segundo estima o economista Henrique Mota, da PUC-RJ, o imposto com alíquotas progressivas teria um impacto arrecadatório entre R \$ 22 bilhões e R $\$ 40$ bilhões, e a tributação de dividendos com as mesmas alíquotas que incidem sobre os salários traria uma receita adicional de $\mathrm{R} \$ 70$ bilhões, a preços de 2016 (CARVALHO, 2020).

Ademais, é preciso evitar a visão simplória de que a macroeconomia possa ser correntemente entendida pela analogia com os orçamentos domésticos. Assim,

32 Estudo recente de um grupo expressivo de tributaristas, liderado pelo Sindicato dos Auditores Fiscais da Receita Federal do Brasil (Sindfisco Nacional), mostra que, somente com as alterações legais — não constitucionais - nas alíquotas do imposto de renda e a criação de um imposto sobre grandes fortunas, seria possível uma arrecadação próxima de R\$200 bilhões anuais.

33 O artigo 153 [EC n 20/98 e EC n 42/2003] da Constituição estabelece: "Compete à União instituir impostos sobre: [...] VII — grandes fortunas, nos termos de lei complementar." 


\section{É direito de}

\section{todos que o}

Estado cumpra

seu dever

de garantir,

mediante

políticas sociais

e econômicas,

a geração de

mecanismos de

proteção social,

e que desenvolva

um conjunto

integrado de

ações para

atingir esse

objetivo de bem

comum. Entre

tais medidas,

desponta a de

universalizar a

cobertura da

renda básica

universal como já demonstrou Keynes, o manejo do crédito e da dívida pública são fundamentais para assegurar a sustentabilidade do crescimento econômico: quando o governo gasta, parte dessa renda retorna sob a forma de impostos $^{34}$. Assim, qualquer estudo deverá considerar que o "gasto líquido" de um programa de renda mínima será, aproximadamente, a metade do custo total do programa, porque parte considerável voltará pelo incremento da arrecadação tributária ${ }^{35}$.

\section{CONCLUSÃO}

É fundamental que se faça o debate pela criação de uma renda básica universal (RBU) em substituição ao abono emergencial, trocando-se um programa provisório e focalizado de transferência de renda por uma política permanente e universal de renda mínima.

Não é proposição utópica e inviável, e diversas estratégias para a sua adoção podem ser empregadas para enfrentar o problema de quem não pode prover com o seu trabalho o sustento material da sua família. As mais diversas vertentes políticas parecem concordar com a necessidade de criação de mecanismos de transferência para os setores menos favorecidos, para resolver esse problema imediato.

É direito de todos que o Estado cumpra seu dever de garantir, mediante políticas sociais e econômicas, a geração de mecanismos de proteção social, e que desenvolva um

34 "Ao acelerar o crescimento econômico com políticas de estímulo, o governo está aumentando também a sua receita. Como visto, o gasto público em momentos de crise econômica, principalmente com alto desemprego e alta capacidade produtiva ociosa, incentiva/promove a ocupação da capacidade, reduz o desemprego e gera crescimento." (ROSSI et al., 2019)

35 Debora Freire e pesquisadores do Centro de Desenvolvimento e Planejamento Regional (Cedeplar) da Universidade Federal de Minas Gerais (UFMG) estimaram o efeito que o auxílio emergencial terá na arrecadação do Governo, já que a renda transferida para as famílias acaba sendo utilizada na compra de bens e serviços e, assim, movimenta a economia e gera arrecadação de impostos. 
conjunto integrado de ações para atingir esse objetivo de bem comum. Entre tais medidas, desponta a de universalizar a cobertura da renda básica universal.

A RBU não vem para substituir benefícios previdenciários de nenhum tipo ou para justificar a redução de serviços públicos: será mais um direito social disponibilizado à população como modo de tornar viva a cidadania, com a finalidade de se buscar o progresso material que todos almejamos e para o qual contribuímos - e que, agora, deve ser mais bem distribuído —, servindo, assim, para abrir caminho para um mundo de maior igualdade e bem-estar social.

Não há razões econômicas sérias para negar aos setores mais vulneráveis de nossa sociedade o direito a uma renda básica em valor, no mínimo, igual ao que é atualmente pago na forma de auxílio emergencial. Trata-se, apenas, de vontade política.

* Desembargador do Tribunal Regional do Trabalho (TRT) da $4^{\text {a }}$ Região, mestre em Direitos Humanos pelo Centro Universitário Ritter dos Reis (UniRitter), doutor em Ciências Jurídicas e Políticas pela Universidade Pablo de Olavide (Sevilha, Espanha), professor da Fundação Escola de Magistratura do Trabalho do Rio Grande do Sul (Femargs) e da Escola Trabalho e Pensamento Crítico, pesquisador do Instituto de Pesquisas e Estudos Avançados da Magistratura e do Ministério Público do Trabalho (Ipeatra) e membro da Associação Juízes para a Democracia (AJD). E-mail: lavargas@ uol.com.br.

** Servidor público do TRT da $4^{\text {a }}$ Região, mestre e doutor em Ciência Política pela Universidade Federal do Rio Grande do Sul (UFRGS).E-mail: walzeus@hotmail.com

Texto recebido em dezembro de 2020; aprovado em dezembro de 2020. 
AZNAR, Guy. Trabalhar menos para trabalharem todos. São Paulo: Scritta, 1995.

BARBOSA, Rogério J. et al. A importância da renda básica no país: o emergencial e o futuro. Nexo, São Paulo, 8 jun. 2020. Disponível em: <www.nexojornal.com.br/ensaio/debate/2020/A-import\%C3\%A2ncia-da-Renda-B\%C3\%A1sica-no-pa\%C3\%ADs-o-emergencial-e-o-futuro>. Acesso em: 16 dez. 2020.

BASIC INCOME EARTH NETWORK. A history. [20--?]. Disponível em: https://basicincome.org/history/. Acesso em 20/12/2020.

BRANCAGLIONE, Marcus. Renda básica libertária: o verdadeiro dízimo. São Paulo: Clube de Autores, 2014.

BRASIL. Câmara dos Deputados. Proposta de Emenda à Constituição n 45, de 2019. Brasília: Câmara dos Deputados, 2020. Disponível em: <www.camara.leg.br/proposicoesWeb/fichadetramitacao?idProposicao=2223716>. Acesso em: 17 dez. 2020.

CARVALHO, Laura. Curto-circuito: o vírus e a volta do Estado. 1. ed. São Paulo: Todavia, 2020.

CASTEL, Robert. As metamorfoses da questão social: uma crônica do salário. Petrópolis: Vozes, 1998.

CASTRO, Augusto. Gastos com auxílio emergencial podem chegar a R\$ 154 bilhões em três meses. Agência Senado, Brasília, 7 maio 2020. Disponível em: <www12.senado.leg.br/noticias/materias/2020/05/07/ gastos-com-auxilio-emergencial-podem-chegar-a-r-154-bilhoes-em-tres-meses>. Acesso em: 3 ago. 2020.

CASTRO, Jorge Abrahão de. Política social, distribuição de renda e crescimento econômico. In: FONSECA, Ana; FAGNANI, Eduardo (Org.). Políticas sociais, desenvolvimento e cidadania: economia, distribuição da renda e mercado de trabalho. São Paulo: Fundação Perseu Abramo, 2017. v. 1. p. 168-197

CERNEV, Adrian Kemmer; PROENÇA, Bruna Auad. Mumbuca: a primeira moeda social digital do Brasil. Revista Brasileira de Casos de Ensino em Administração, São Paulo, v. 6, n. 2, jul.-dez. 2016. Disponível em:<http://dx.doi.org/10.12660/gvcasosv6n2c15>. Acesso em: 17 dez. 2020.

COELHO, Rogério Viola. A insuficiência como premissa neoliberal. Brasil de Fato, Porto Alegre, 8 maio 2020.

COLL, Liana. Capitalismo virótico: um sistema destrutivo que só será superado através das lutas sociais, diz Ricardo Antunes. 8 out. 2020. Disponível em: https://www.unicamp.br/unicamp/ noticias/2020/10/08/capitalismo-virotico-um-sistema-destrutivo-que-so-sera-superado-atraves-das. Acesso em 16 dez. 2020.

COSTA, Ana Maria; RIZZOTTO, Maria Lucia Frizon; LOBATO, Lenaura Vasconcelos Costa. Na pandemia da covid-19, o Brasil enxerga o SUS. Saúde em Debate, Rio de Janeiro, v. 44, n. 125, abr.-jun. 2020. COVID-19: ONU defende renda básica universal para combater desigualdade crescente. DMT, 12 maio 2020. Disponível em: <www.dmtemdebate.com.br/covid-19-onu-defende-renda-basicauniversal-para-combater-desigualdade-crescente>. Acesso em: 15 jun. 2020.

DANÉRIS, M. (Coord.). Segunda renda: programa de renda mínima garantida ao trabalhador formal subocupado. [S.I.]: Programa Segunda Renda; Instituto Novos Paradigmas, 2018.

DIEESE. Medidas adotadas por vários países para conter os efeitos econômicos da pandemia do coronavírus. Nota Técnica, São Paulo, n. 224, 23 mar. 2020.

DOMBEY, Daniel; SANDBU, Martin. Espanha quer criar programa de renda mínima para 2,3 milhões de pessoas. Valor Econômico [on-line]. 29 mai. 2020. Disponível em: https://valor.globo.com/mundo/ noticia/2020/05/29/espanha-quer-criar-programa-de-renda-minima-para-23-milhoes-de-pessoas. ghtml. Acesso em 3/8/2020.

DUQUE, Daniel. Renda básica: é hora de o Brasil ousar em sua política social?. Blog do Ibre, 27 maio 2020. Disponível em: <https://blogdoibre.fgv.br/posts/renda-basica-e-hora-de-o-brasil-ousarem-sua-politica-social>. Acesso em: 12 jul. 2020.

ECONOMIA informal cresce pelo $5^{\circ}$ ano seguido no país e corresponde a $17,3 \%$ do PIB, aponta estudo. G1, 18 dez. 2019. Disponível em: <https://g1.globo.com/economia/noticia/2019/12/18/ economia-informal-cresce-pelo-5o-ano-seguido-no-pais-e-corresponde-a-173percent-do-pibaponta-estudo.ghtml>. Acesso em: 12 mar. 2020.

ENGELS, Friedrich. A origem da família, da propriedade privada e do Estado. 15. ed. Rio de Janeiro: Bertrand Brasil, 2000.

FRIEDMAN, Milton. Capitalismo e liberdade. Rio de Janeiro: Arte Nova, 1975. 
INSTITUTO PALMAS. Conheça a moeda mumbuca. 27 jun. 2018. 4 min. Disponível em: <www. youtube.com/watch?v=q8S2enuj9-M>. Acesso em: 17 dez. 2020.

MELLO, Carolina Junqueira Homem de. Focalização de políticas públicas: teoria e prática. 2004. Dissertação (Mestrado em Economia). Instituto de Economia, Universidade Estadual de Campinas, Campinas, 2004.

LAZZARIN, Sonilde Kugel. A (in)seguridade social em tempos de pandemia: a renda básica universal como possível solução ao precariado e à crescente desigualdade social no Brasil. Porto Alegre: HS Editora, 2020.

LI, Cheng. Emprego e bem-estar social na era da inteligência artificial. Carta Social e do Trabalho, Campinas, v. 34, p. 13-22, jul.-dez. 2016.

LIMONCIC, Flávio. A grande transformação da economia americana: o New Deal e a promoção da contratação coletiva do trabalho. In: LIMONCIC, Flávio; MARTINHO, Francisco Carlos Palomanes (Org.). A Grande Depressão: política e economia na década de 1930 - Europa, Américas, África e Ásia. Rio de Janeiro: Civilização Brasileira, 2009.

MÉDA, Dominique. Tres escenarios para el futuro del trabajo. Revista Internacional del Trabajo, v. 138, n. 4, p. 675-702, 2019.

MUNDOS DO TRABALHO. Emprego, trabalho e renda para garantir o direito à vida. Grupo de Trabalho: Reformas. Cesit, Campinas, 2020.

NASSIF, Luis. Por que a renda básica vai ajudar na recuperação do PIB. GGN, São Paulo, 22 maio, 2020. Disponível em: <https://jornalggn.com.br/coluna-economica/porque-a-renda-basica-vaiajudar-na-recuperacao-do-pib-por-luis-nassif>. Acesso em: 16 dez. 2020.

OLINTO, Roberto. Economia informal (Brasil 2012-2019): um exercício lúdico especulativo - parte II. Blog do Ibre, 12 mar. 2020. Disponível em: <https://blogdoibre.fgv.br/posts/economia-informalbrasil-2012-2019-um-exercicio-ludico-especulativo-parte-ii>. Acesso em: 3 ago. 2020.

PARIJS, Philippe van. Capitalismo de renda básica. Lua Nova, n. 32, p. 69-91, 1994.

Por que os surfistas devem ser alimentados: o argumento liberal em defesa de uma renda básica incondicional. Revista Brasileira de Ciência Política, n. 15, p. 229-269, 2014.

PIMENTEL FILHO, José Eduardo. Da disciplina à necropolítica, o papel do trabalho e da seguridade em Foucault e na atualidade. Griot, v. 20, n. 1, p. 131-143, 2020.

QUASE metade da população global vive abaixo da linha da pobreza. DW, 18 out. 2018. Disponível em: <www.dw.com/pt-br/quase-metade-da-popula\%C3\%A7\%C3\%A3o-mundial-vive-abaixo-dalinha-da-pobreza/a-45933653>. Acesso em: 16 dez. 2020.

RBRB. Sobre a renda básica. Rede Brasileira de renda básica, 2020. Disponível em: <http:// rendabasica.com.br/sobre-a-renda-basica>. Acesso em: 6 ago. 2020.

RENDA Mínima Vital aprovada. Espanha Fácil, 1 jun. 2020. Disponível em: <www.espanhafacil.com/ blog/renda-minima-vital-aprovada>. Acesso em: 1 jul. 2020.

ROCKWELL, Lew. Vouchers escolares: o caminho mais "eficiente" para a socialização da educação. Mises Brasil, 25 set. 2014. Disponível em: <www.mises.org.br/Article.aspx?id=1942>. Acesso em: 20 jun. 2020.

ROSSI, Pedro et al. Austeridade fiscal e o financiamento da educação no Brasil. Educação \& Sociedade, Campinas, v. 40, dez. 2019.

ROTHBARD, Murray N. Elucidando Milton Friedman e a Escola de Chicago. Mises Brasil, 5 ago. 2011. Disponível em: <www.mises.org.br/Article.aspx?id=1065>. Acesso em: 4 ago. 2020.

SILVA, Josué Pereira da. Nota sobre o conceito de "reformas revolucionárias" de André Gorz. Caderno CRH, v. 30, n. 81, p. 1-14, set.-dez. 2017,

SOUZA, Jessé. A classe média no espelho: sua história, seus sonhos e ilusões, sua realidade. Rio de Janeiro: Estação Brasil, 2018.

SUPLICY, Eduardo Matarazzo. Renda de cidadania: a saída é pela porta. São Paulo: Cortez, 2020.

VILELA, Pedro Rafael. Para economistas , o discurso de que Estado não podia aumentar gastos não se sustenta. Brasil de Fato, Brasília, 10 maio 2020. Disponível em: <www.brasildefato.com. br/2020/05/10/para-economistas-o-discurso-de-que-estado-nao-podia-aumentar-gastos-nao-sesustenta>. Acesso em: 14 jun. 2020. 